\title{
1 Corrosion of pure magnesium and WE43 magnesium alloy studied by advanced acoustic emission analysis
}

\section{Michal Knapek ${ }^{\mathrm{a}}$, Peter Minárika , Jan Čapek ${ }^{\mathrm{ab}}$, Robert Krála , Jiří Kubásekc, František Chmelík ${ }^{\mathrm{a}}$}

\author{
${ }^{a}$ Charles University, Faculty of Mathematics and Physics, Ke Karlovu 5, 12116 \\ Prague, Czech Republic
}
bPaul Scherrer Institute, Laboratory for Neutron Scattering and Imaging, 5232 PSI
Villigen, Switzerland

\begin{abstract}
cUniversity of Chemistry and Technology, Department of Metals and Corrosion Engineering, Technická 5, 166 28, Prague, Czech Republic *corresponding author: knapek@karlov.mff.cuni.cz
\end{abstract}

\begin{abstract}
Corrosion behaviour of magnesium and WE43 magnesium alloy in $1 \mathrm{M} \mathrm{NaCl}$ aqueous solution was studied by potentiodynamic polarisation and advanced acoustic emission (AE) analyses. The AE parameters suitable for the monitoring of corrosion in magnesium were shown to be the AE counts, rise time, and duration. Moreover, the mechanisms of corrosion in these materials, i.e. the ion exchange, rupture of the protective film, and the pitting corrosion were identified and their evolution was followed by the novel Adaptive sequential k-means clustering technique. The presented methods can be also suitable for monitoring of different materials and for industrial applications.
\end{abstract}

\section{Keywords:}

Pitting corrosion; acoustic emission; polarisation, magnesium; clustering.

\section{Introduction}

Magnesium and magnesium alloys are prominent candidates for modern applications due to their low density and exceptional mechanical properties [1, 2]. Moreover, alloying of magnesium can result in a production of alloys which combine outstanding mechanical properties with biocompatibility and increased corrosion resistance [3-5]. On the other hand, the corrosion behaviour remains a substantial concern as magnesium is a base metal and exhibits high reactivity [6-8]. Magnesium and its alloys, as well as many other metals, are disposed to pitting corrosion when exposed to environments containing chloride ions [6, 9, 10]. Pitting corrosion was documented to consist of three stages: (i) pit nucleation, (ii) development of metastable pits, which either repassivate or (iii) grow into stable ones, which further propagate in the material [11].

This document is the accepted manuscript version of the following article:

Knapek, M., Minárik, P., Čapek, J., Král, R., Kubásek, J., \& Chmelík, F. (2018). Corrosion of pure magnesium and a WE43 magnesium alloy studied by advanced acoustic emission analysis. Corrosion Science, $145,10-15$. https://doi.org/10.1016/j.corsci.2018.09.006 
When immersed in the $\mathrm{NaCl}$ aqueous solution, $\mathrm{Mg}$ oxidises to form $\mathrm{Mg}^{+}$. Excessive electrons in the material react with $\mathrm{H}^{+}$ions present in the solution, resulting in the formation of $\mathrm{H}_{2}$ gas. Furthermore, $\mathrm{Mg}^{2+}$ reacts with $\mathrm{OH}^{-}$species forming $\mathrm{Mg}(\mathrm{OH})_{2}$ corrosion film [8, 12]. Although the partial corrosion mechanisms of $\mathrm{Mg}$ are quite complex, the overall process can be expressed as $[8,13]$ :

$\mathrm{Mg}+2 \mathrm{H}_{2} \mathrm{O} \rightarrow \mathrm{Mg}(\mathrm{OH})_{2}+\mathrm{H}_{2}$

The $\mathrm{Mg}(\mathrm{OH})_{2}$ film provides only limited corrosion protection and is readily attacked by aggressive $\mathrm{Cl}^{-}$ions present in the solution. The formation of more resistant $\mathrm{MgO}$ corrosion layer with thickness on the order of nanometers was also documented underneath the porous $\mathrm{Mg}(\mathrm{OH})_{2}$ layer due to its dehydration [15, 16, 7]. Alloying elements present in the WE43 alloy were shown to be incorporated into the corrosion film and lead to increased corrosion resistance [17-19]. Moreover, magnesium exhibits an anomalous phenomenon known as the negative difference effect (NDE), i.e. the rate of cathodic corrosion reaction (which is accompanied by the $\mathrm{H}_{2}$ gas evolution) increases with increased anodic potential [20,21].

Electrochemical measurements used to monitor corrosion typically do not provide comprehensive information about the underlying processes and corrosion rates. On the other hand, the acoustic emission (AE) technique is a non-destructive technique particularly sensitive to rapid microstructural changes. Such processes are accompanied by a release of energy in the form of transient elastic waves, which can be recorded on the material surface [22]. The AE technique has been successfully employed to monitor pitting and other types of corrosion (e.g. [10, 11, 23-31]). For example, representative AE parameters effective for corrosion monitoring were identified to be the AE counts, rise time and frequency $[24,29,11]$ or corrosion source recognition in the frequency domain was documented in [29-31]. The vast majority of works dealing with the AE monitoring of corrosion processes, however, focuses on stainless steels. A recent review paper of Esmaily et al. [32] and references therein bear witness that the AE technique is widely omitted in the corrosion studies of magnesium and its alloys even though it can provide unique in-situ information, which can be hardly revealed by commonly used electrochemical, imaging, and spectroscopy methods. There is a very limited number of AE studies concerning corrosion in magnesium [10,33-35] and these existing papers evaluate only basic AE parameters.

In this work, we present a complex AE analysis in the form of AE signal parameterisation (in the time domain) combined with a novel method - Adaptive sequential k-means (ASK) clustering analysis (in the frequency domain). The ASK analysis provides a comprehensive set of statistical parameters of the AE signals, which are used to identify AE signal clusters corresponding to different corrosion mechanisms. Moreover, this specially modified k-means algorithm is sequential (i.e. non-iterative) and, therefore, can be applied in real time, unlike conventional time-consuming iterative clustering methods. The pioneering paper on the ASK analysis was published in 2014 [36] and the analysis has since been successfully applied to monitor e.g. deformation mechanisms in $\mathrm{Mg}[37,38]$ or a similar approach was adopted for structural health monitoring [39]. To our knowledge, the ASK technique has not yet been employed to study corrosion processes.

The main objective of this study is, therefore, twofold. First, as there is only a limited number of related works, this study aims to contribute to the understanding of corrosion processes in $\mathrm{Mg}$ and its alloys using the AE technique. Second, the recently developed ASK analysis will 
be applied for the first time to monitor corrosion processes. The ASK algorithm provides complex information on the dynamics of corrosion processes occurring in the studied materials and can be also utilised in the future to study corrosion in different materials of interest.

\section{Materials and methods}

The materials investigated in this work, magnesium (content of impurities: $\mathrm{Al}-0.018 \mathrm{wt} . \%, \mathrm{Si}$ - 0.015 wt. \%, Mn -0.015 wt.\%, and $\mathrm{Zn}-0.003$ wt.\%) and magnesium alloy WE43 (Mg - 3.8 $w t \% \mathrm{Y}-2.6 \mathrm{wt} \% \mathrm{RE}-0.45 \mathrm{wt} \% \mathrm{Zr}-0.01 \mathrm{wt} \% \mathrm{Mn}$ ), were supplied in the as-cast condition. In order to minimise the influence of secondary phases, the cast billets were homogenised and solution treated at $525{ }^{\circ} \mathrm{C}$ for $16 \mathrm{~h}$ (T4 treatment) and quenched into water. The grain size after the treatment was $\sim 1000$ and $\sim 100 \mu \mathrm{m}$ for the $\mathrm{Mg}$ and WE43 materials, respectively. Samples with dimensions of $10 \times 10 \times 50 \mathrm{~mm}^{3}$ were cut from both materials and one side of each sample was wet ground using a 1200 grit $\mathrm{SiC}$ paper shortly before each test.

A standard three-electrode setup was used for the electrochemical experiments with a saturated calomel (SCE) reference electrode (RE), sample operating as a working electrode (WE), and a platinum plate serving as a counter electrode (CE). The schematic view of the experimental set-up is shown in Fig. 1. An acrylic glass cylindrical cell with dimension of $\varnothing 100$ $\mathrm{mm} \times 150 \mathrm{~mm}$ was used. The cell contains a hole with a diameter of $8 \mathrm{~mm}$, situated $75 \mathrm{~mm}$ above the cylinder base. From the outer side, the hole is encompassed by an elastomer O-ring. The polished face of the sample was placed over the hole and mounted (pushed) from the outer side with the help of a screw. The samples were exposed at the room temperature to neutral $0.1 \mathrm{M} \mathrm{NaCl}$ solution prepared using deionised water. The solution was agitated during each test by a magnetic stirrer with a $30 \mathrm{~mm}$ stirring bar operating at $150 \mathrm{rpm}$. Potentiodynamic polarisation tests were carried out from $-150 \mathrm{mV}$ to $+250 \mathrm{mV}(\mathrm{Mg})$ or +500 $\mathrm{mV}$ (WE43) with respect to the open circuit potential (OCP) after $300 \mathrm{~s}$ of stabilization. The tests were performed with a scan rate of $1 \mathrm{mV} / \mathrm{s}$ using the potentiostat Autolab PGSTAT128N.

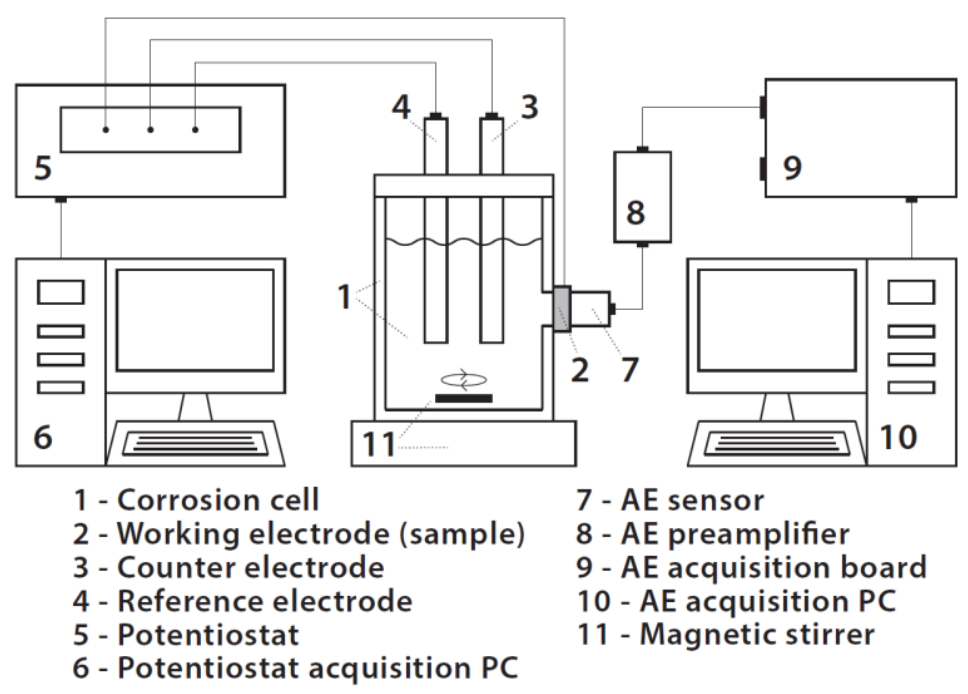

Figure 1. Schematic diagram of the experimental set-up used in this study. 
The AE response was monitored concurrently using a computer controlled PAC (Physical Acoustics Corporation) PCI-2 acquisition board. Piezoelectric wideband PAC Micro30S AE sensor was used in order to record the broad AE signal spectra needed for the analyses. This sensor features a ceramic face preventing electrical contact with the sample, which might give rise to the noise originating in the polarisation test electrical circuit. The AE sensor was mounted directly on the sample using a silicon grease and a wooden clip. The AE signal was recorded with a sampling rate of $2 \mathrm{MHz}$ and preamplified by a PAC 2/4/6 preamplifier (60 $\mathrm{dB}$ gain).

The AE signal was evaluated using two different methods:

1. The AE events were individualised using a standard threshold-based evaluation technique (ASTM E1316) with peak definition time of $0.4 \mathrm{~ms}$, hit definition time of 0.8 $\mathrm{ms}$, hit lockout time of $1 \mathrm{~ms}$, and maximum event duration of $100 \mathrm{~ms}$. The AE signal noise level $(22-23 \mathrm{~dB})$ was determined before the actual tests using identical experimental set-up as shown in Fig. 1, but with an empty corrosion cell not filled with the solution. Moreover, the AE response was recorded several seconds prior to the start of each individual test in order to verify the noise conditions, which remained constant for all the experiments. The threshold level was set to $25 \mathrm{~dB}$, i.e. slightly above the noise level. Based on the above-mentioned individualisation settings, the AE event parameters such as counts, amplitude, duration, and rise time were extracted.

2. The raw AE signal was stored and post-processed by the ASK technique established recently by Pomponi and Vinogradov [36]. This technique is particularly effective in correlating the AE signals with different emitting sources, based on differences in the power spectral density function (PSD) of AE signals. In short, the algorithm sections the AE signal into "time windows". In this study, we used a time window of $2 \mathrm{~ms}$. Based on the PSD function of the first window and the statistical parameters (median frequency, energy, kurtosis, etc.), first cluster is defined. The procedure is progressively repeated window-by-window. If parameters of the window are statistically similar to the already existing cluster, the window will contribute to this cluster. Otherwise, a new cluster is created. In this way, statistically well-separated clusters are attained and dominant sources (concurrent contribution of multiple weaker sources is not excluded) of the AE signal can be finally assigned to individual clusters. It should me mentioned that the method is non-iterative and non-supervised (number of clusters in not fixed), therefore, it can be employed for real-time applications. For detailed description of the algorithm and the input parameters see [36].

Microstructure of the samples was observed using the light microscope Olympus GX51. The micrographs were taken before the potentiodynamic polarisation tests and, furthermore, the polarisation tests (as described above) were repeated and stopped at different points of the polarisation process: (i) before the breakdown potential and (ii) after the breakdown potential, as shown in Fig. 2 and discussed in the next sections. The samples were immediately detached and dried using compressed air and the surface analysis was performed.

\section{Results and discussion}




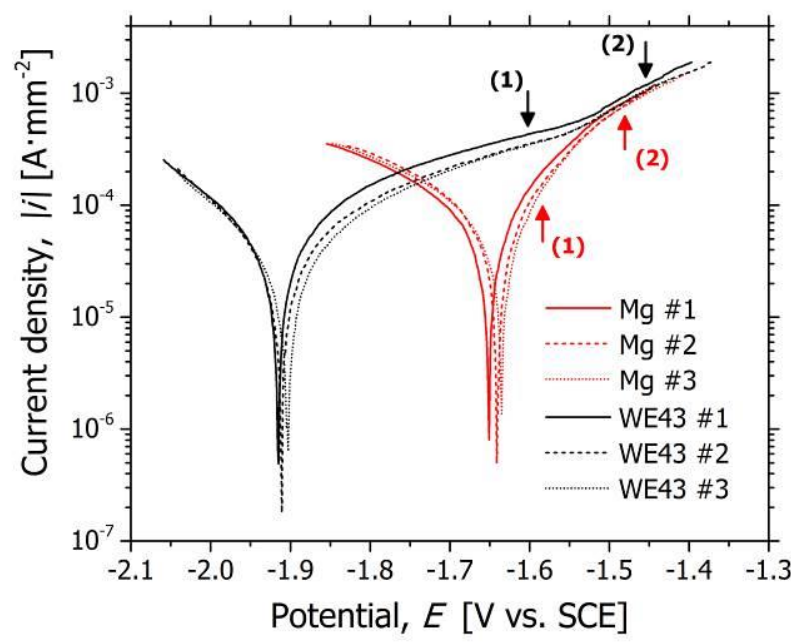

Figure 2. Anodic potentiodynamic polarisation scans performed on pure $\mathrm{Mg}$ (red) and WE43 magnesium alloy (black). Three samples of each material were tested.

The results of anodic potentiodynamic polarisation measurements are presented in Fig. 2. The scans were repeated three times for both materials and the results showed good reproducibility. Measured corrosion potentials for $\mathrm{Mg}$ (-1.65 V vs. SCE) and WE43 alloy (-1.92 $\mathrm{V}$ vs. SCE) are in the range of values reported in the literature [40], confirming that WE43 is one of the few alloys less noble than pure $\mathrm{Mg}$. On the other hand, polarisation resistance, $R_{\mathrm{p}}$, calculated according to the Stern-Geary method was substantially higher for the WE43 alloy. The values of $R_{\mathrm{p}}$ were $230 \pm 5 \Omega . \mathrm{cm}^{2}$ for $\mathrm{Mg}$ and $490 \pm 50 \Omega . \mathrm{cm}^{2}$ for WE43. The difference is caused by enhanced surface passivation in WE43 compared to pure Mg [10]. During the test, the current density in WE43 samples starts to increase significantly at the potential of $-1.55 \mathrm{~V}$ vs. SCE, indicating a breakdown potential of pitting corrosion [41]. At this point, the polarisation curves of both materials start to overlap. In order to verify the concept of breakdown potential, surface observations were performed before the test and at points indicated by arrows in Fig.
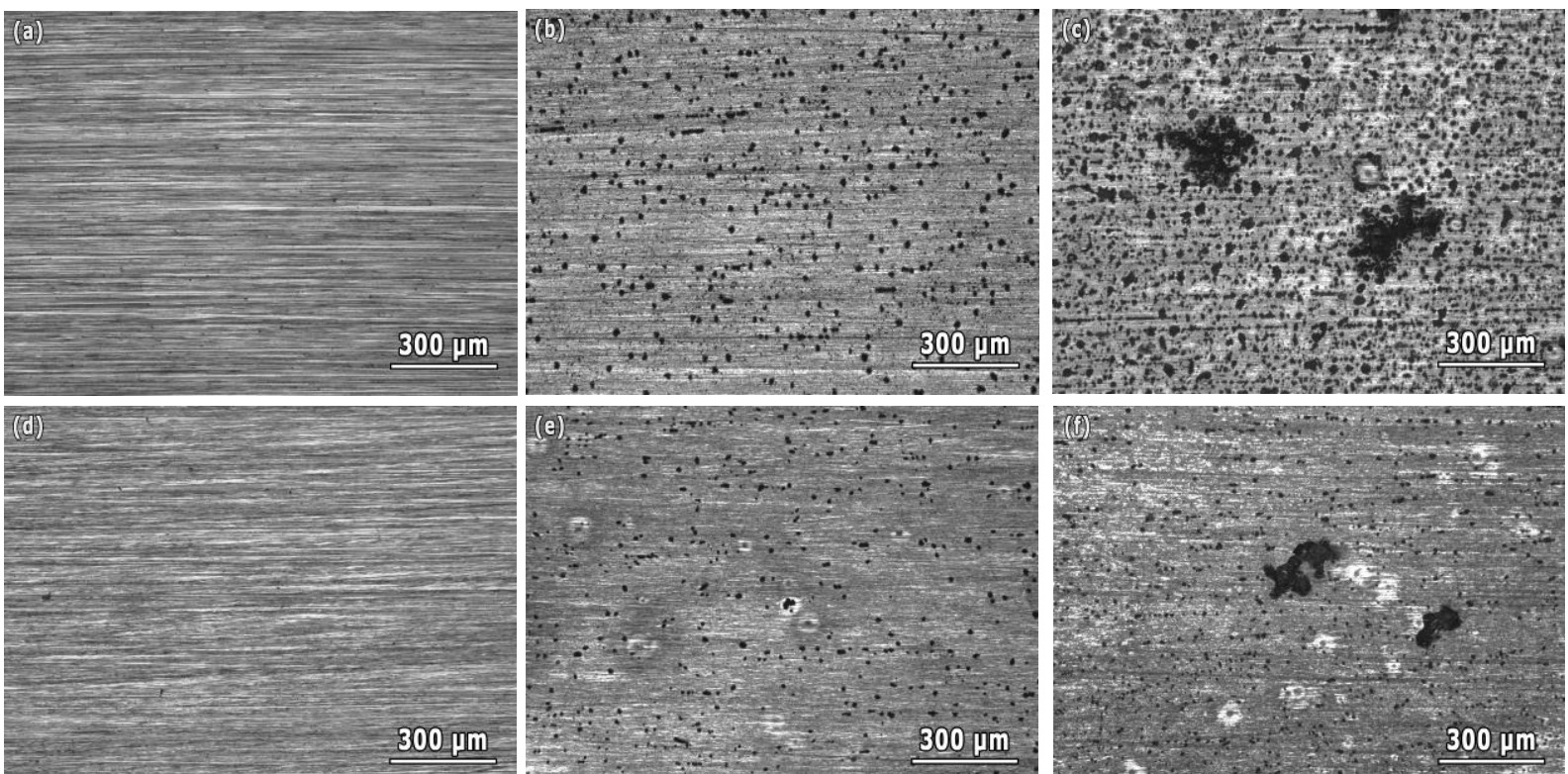

Fig. 3. Surface observations before the anodic polarisation test (a) pure Mg (d) WE43 alloy; before the onset of stable pitting corrosion indicated by arrows (1) in Fig. 1, (b) pure $\mathrm{Mg}$, (e) WE43 alloy; and after the onset of stable pitting corrosion indicated by arrows (2) in Fig. 1 (c) pure Mg, (f) WE43 alloy. 
2. The surface of pure Mg was also examined even though no distinct breakdown potential could be resolved from the curves. It can be seen in the micrographs that surfaces of both materials in the stage highlighted with arrows (1) in Fig. 2 are disrupted by numerous small pits (see Fig. 3b and 3e). In the stage marked by arrows (2), large pits can be seen on both surfaces (Fig. 3c and 3f), indicating the presence of stable pitting corrosion in both materials. Despite the formation of several large pits, size of small pits in the WE43 alloy remains practically constant. Conversely, the surface of pure $\mathrm{Mg}$ in this stage is attacked more significantly, leading to the formation of pit agglomerates and considerably larger fraction of disrupted surface. White spots observed on the WE43 surface are most likely the locations where $\mathrm{H}_{2}$ bubbles formed. Corrosion products may accumulate locally in these regions [7].

In Fig. 4, the AE signal parameters recorded during potentiodynamic tests are presented. The AE data were recorded during all three tests on both materials, using the same AE sensor, and showed very good reproducibility; therefore, only one set of data is presented for each material. Fig. 4a shows the AE response of pure $\mathrm{Mg}$ sample in terms of the raw AE signal and the AE event parameters (counts, amplitude, duration, and rise time). Absolute value of the current density, $|i|$, is depicted along with the time derivative, $\mathrm{d} i / \mathrm{d} t$, in order to allow easier identification of trends in the potential-current curve. The AE response is relatively constant up to $\sim 240 \mathrm{~s}(+90 \mathrm{mV}$ vs. OCP). Thereafter, the AE activity rises as is demonstrated by a gradual increase of the values of essentially all evaluated AE parameters until the end of the test. The WE43 alloy (Fig. 4b) exhibits rather different behaviour. In the beginning of the scan up to 100
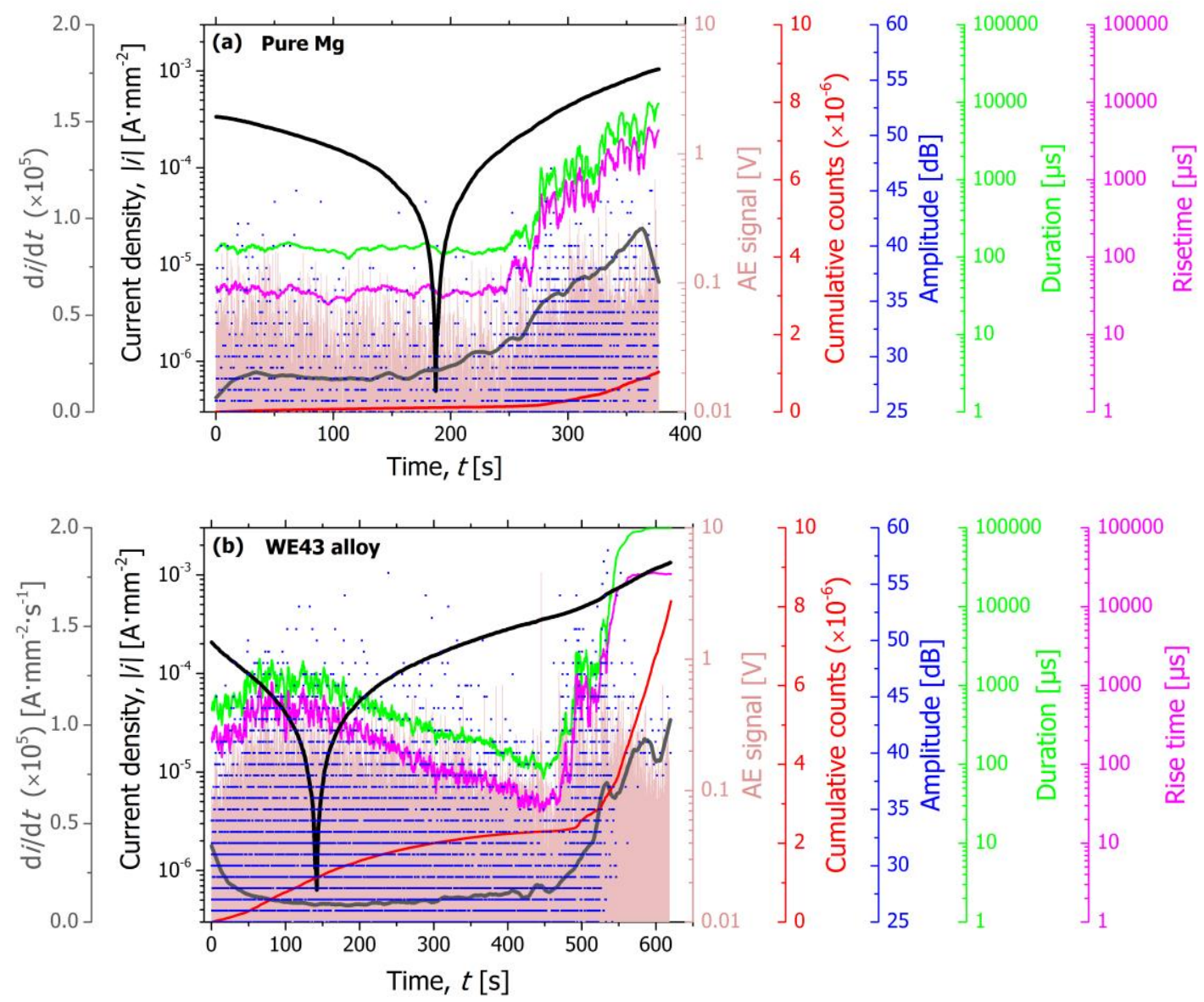

Fig. 4. Acoustic emission parameters recorded during the anodic polarisation test on (a) pure Mg and (b) WE43 alloy. Individualization of the AE parameters was performed using a standard threshold-based detection. 

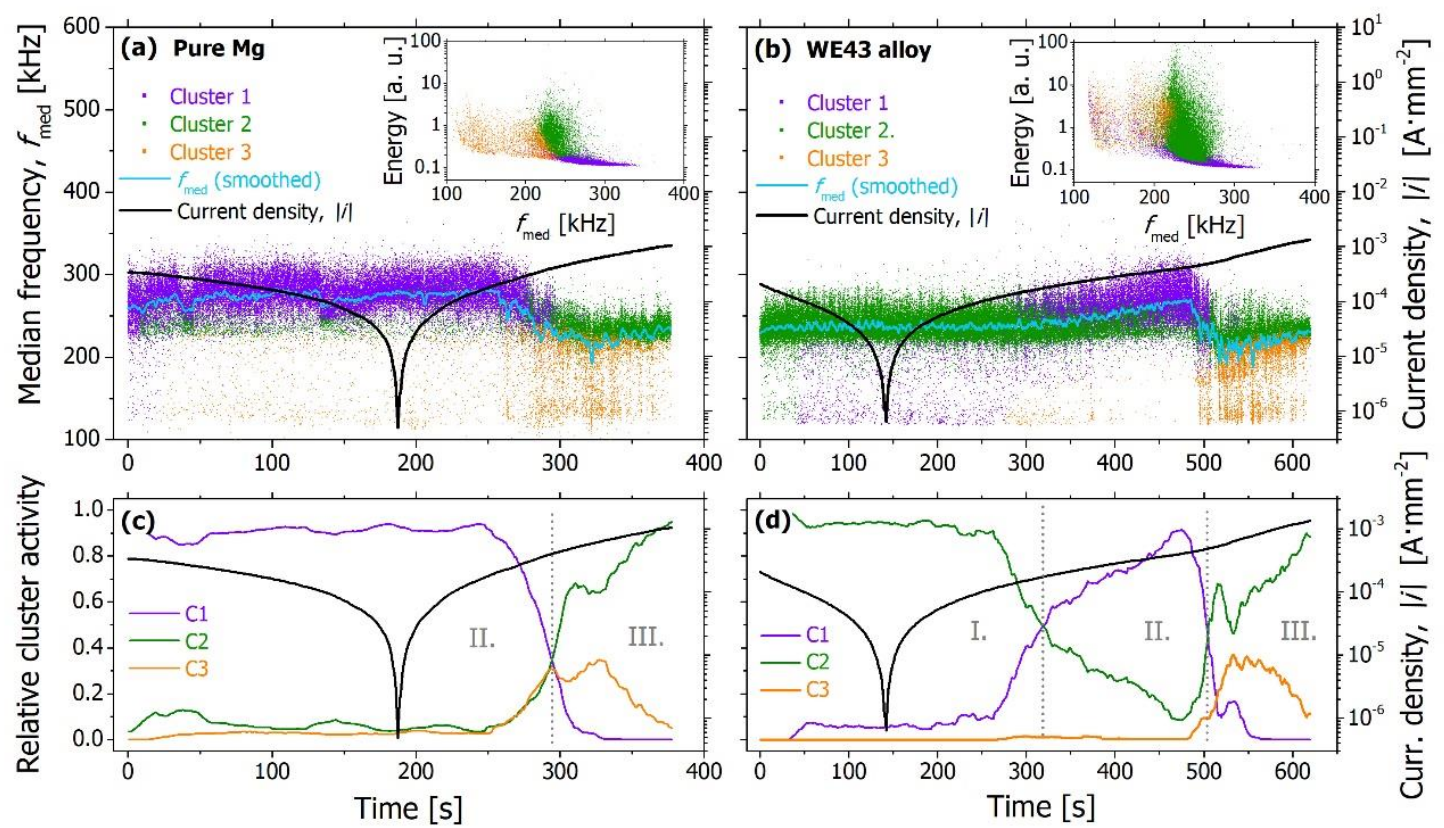

Fig. 5. Results of the ASK clustering analysis performed on (a) pure Mg and (b) WE43 alloy during the anodic polarisation test. Three clusters (marked C1, C2, and C3 were identified). 2D projection of the cluster is depicted in terms of Median frequency vs. Time and Median frequency vs. Energy (inset) diagrams. The time evolution of relative activity of clusters in (c) pure $\mathrm{Mg}$ and (d) WE43 alloy is also displayed.

$\mathrm{s}(-70 \mathrm{mV}$ vs. OCP), AE activity slightly increases and then, up to $\sim 450 \mathrm{~s}$ (+300 mV vs. OPC), continually decreases. Subsequently, a gradual escalation of the AE activity takes place as the $\mathrm{AE}$ parameters rise to very high values in the end of the test. Note that enhanced AE activity in both materials begins between the points (1) and (2) in Fig. 2. Therefore, it can be related to the initiation of pitting corrosion which is also suggested by the micrographs in Fig. 3 and the derivative, $\mathrm{d} i / \mathrm{d} t$, in the case of both materials. Note also that the transition from cathodic to anodic part of the scan does not produce observable changes in the AE response. The overall $\mathrm{AE}$ activity is higher in the WE43 alloy than in pure $\mathrm{Mg}$ as demonstrated by the cumulative AE counts reaching $8 \times 10^{6}$ in the end of the test compared with $1 \times 10^{6}$ in the case of pure $\mathrm{Mg}$. This difference remains substantial even if the values are normalised by the duration of the scan, $\sim 400 \mathrm{~s} \mathrm{(Mg)}$ and $\sim 600 \mathrm{~s}$ (WE43). Furthermore, evolution of this parameter during the scans can be regarded as indicator of the corrosion activity. It was shown that $\mathrm{AE}$ counts are in many materials proportional to the corrosion rate [23]. On the other hand, AE amplitudes seem to be a less informative and reliable parameter. Although some trends can be observed in the stages when pitting corrosion takes place, the AE amplitudes sporadically take on high values even in earlier stages of the test when the AE activity is relatively low. Parameters duration and rise time are seemingly in a very good mutual correlation. It must be noted that for the sake of clarity curves of both these parameters were smoothed (moving average, 5000 points). Therefore, the correlation between these two quantities does not mean that individual AE event with long duration necessarily exhibits long rise time. The curves rather follow the trends at averaged time scales larger than duration of individual AE events. Both of these parameters are particularly sensitive to the onset and progress of pitting corrosion. However, in order to explain the corrosion dynamics at earlier stages it is necessary at this point to perform the $\mathrm{AE}$ analysis in the frequency domain and to discuss the corrosion processes occurring during the scans. 
Fig. 5 presents the results of the ASK clustering analysis. Representation of clusters in the 2D space in terms of time vs. median frequency and median frequency vs. energy (inset graphs) projections for the Mg and WE43 samples can be seen in Fig. 5a and 5b, respectively. Note that even though clusters in the 2D projection may appear to overlap, their distance is defined by many statistical parameters of the signal and, therefore, are generally well separated. In addition, Fig. $5 \mathrm{c}$ and $5 \mathrm{~d}$ show evolution of the activity of individual clusters during the scan. The algorithm identified three clusters which are depicted in different colours. Average median frequency (moving average, 1000 points) of the complete AE signal, i.e. all clusters taken together, is also plotted. Basic examination of the evolution of median frequency, when compared with the current-potential curves in Fig. 2 and the analysis of AE parameters in Fig. 4 , demonstrates strong sensitivity of this parameter to the onset of pitting corrosion. The corrosion mechanisms active during particular stages of polarisation must be, however, discussed in order to be able to ascribe some physical significance to the identified clusters.

Passivation films, $\mathrm{Mg}(\mathrm{OH})_{2}$ and $\mathrm{MgO}$, can control the cation egress and water diffusion between the metal substrate and the electrolyte [17]. However, their corrosion protection is only partial due to the presence of aggressive $\mathrm{Cl}^{-}$ions in the $\mathrm{NaCl}$ solution [13]. For this reason, a more uniform corrosion is also supposed to occur before the actual stable pitting corrosion. The uniform corrosion was shown to generate short, relatively weak AE signals originating in the local stress changes on the sample surface due to the ion exchange and the deposition of corrosion products $[25,27]$. It was documented that the actual pitting corrosion is accompanied by enhanced evolution of $\mathrm{H}_{2}$ bubbles as a result of hydrolysis of corrosion products. Due to the friction of the bubbles along the pit walls, resulting AE is of resonant type, i.e. the signals feature long duration, rise time, and high count rate. This process is the most prominent corrosion AE source. Such signals were also shown to be very energetic [27] and to exhibit relatively low frequency spectra [42]. Moreover, decrease of the frequency due to higher rate of microstructural changes is a typical feature of the AE response [36]. It should be also noted that absolute values of the AE signal frequencies and energies may differ from one experimental set-up to another due to the different signal transfer functions (as a result of setup geometry and AE sensor used). Therefore, only relative changes in these quantities should be evaluated.

Based on the description of the corrosion sources of $\mathrm{AE}$ and the outlined theory of corrosion processes in magnesium, we were able to assign particular mechanisms to the individual clusters. As shown in the inset graphs in Fig. 5a and 5b, Cluster 1 (violet) represented AE events with relatively low energy and high frequency, Cluster 2 (green) represented AE events with relatively high energy and moderate frequency, and Cluster 3 (orange) represented AE events with relatively high energy and low frequency. For better clarification of the physical meaning of each cluster, time evolutions of the activity of individual clusters shown in Fig. $5 \mathrm{c}$ and Fig. $5 \mathrm{~d}$ were divided into characteristic stages. Stage I (present only in WE43 sample) is characterised by a high activity of Cluster 2, stage II by a high activity of Cluster 1, and stage III by a high activity of Clusters 2 and 3. Stage I was observed only in the WE43 alloy, whereas stages II and III were identified in both investigated materials. It was already discussed that pure magnesium forms less protective corrosion layer compared to the WE43 alloy; therefore, the induced electron exchange (the cathodic part) and the ion exchange (the anodic part) through the layer is easier and results in acoustic events of low energy and high frequency stage II (Cluster 1 - uniform corrosion) in Fig. 5c. On the other hand, the same part of the polarisation curve of the WE43 alloy in Fig. 5d, i.e. stage I, is represented by a high activity in 
Cluster 2, which is characterised by acoustic events of higher energy and decreased frequency. These characteristics can be attributed to a much stronger protectivity of the corrosion layer formed on the WE43 alloy surface. As a result, there are fewer sites where the electron/ion exchange takes place, but the process is accompanied by an increased transfer of energy. This also agrees with the microscopic observations in Fig. 3, which show lower surface damage for WE43 sample than for Mg sample. Only when the anodic overpotential is sufficiently high, the weakening of the protective layer appears, resulting in the activity in Cluster 1 and transition into Stage II (at $~ 300$ s), which displays similar characteristics as in the case of $\mathrm{Mg}$ sample. The local failures (pits) in the protective layer of WE43 sample are shown in Fig. 3e. Gradual increase of the number of the pits results in continuous increase of the Cluster 1 activity at the expense of the activity in the Cluster 2. Looking back at Fig. 4a, these stages of corrosion in pure $\mathrm{Mg}$ are characterised by a stable $\mathrm{AE}$ emission with relatively low count rate and low duration and rise time of the AE events, which is justified by the stability of $\mathrm{Mg}$ clusters documented by the ASK results shown in Fig. 5a and Fig 5c. As already mentioned, the WE43 alloy (Fig. 5b) exhibits less stable behaviour. It correlates also with slightly more erratic evolution of the parameters of $\mathrm{AE}$ events in Fig. 4b. The maximum in the AE event duration and rise time at $\sim 100 \mathrm{~s}$ is not perfectly clear at the moment, however, this non-stable behaviour is most likely a result of increased complexity of corrosion processes in WE43 due to the effect of alloying elements. Nevertheless, relatively short duration and rise time of the AE events confirm that short, burst-like AE events are characteristic for these stages of corrosion. On the other hand, transition from stage I to stage II at $200 \mathrm{~s}$ in the WE43 sample (Fig. 5d) is captured by the decrease in the slope of cumulative counts in Fig. 4b. Finally, with the onset of stable pitting corrosion, the median frequency is reduced and Cluster 3 becomes active in both materials (Fig. 5a-d). This is a result of the growth of stable pits accompanied by the distinctive formation of $\mathrm{H}_{2}$ bubbles. With increasing overpotential, electromotive force for the ion transfer increases and leads also to the resuming of Cluster 2 activity. The parameters duration and rise time (Fig. $4 \mathrm{a}$ and $4 \mathrm{~b}$ ) increase significantly in this stage, suggesting a continuous resonant character of the $\mathrm{AE}$ signals due to the evolution $\mathrm{of}_{2} \mathrm{H}_{2}$ bubbles and accelerated corrosion rate. Increased corrosion rate in this stage of the test might be also partially related to the negative difference effect. The processes observed on the onset of stable pitting are somewhat more pronounced and rapid in the WE43 alloy. Moreover, the AE cumulative counts value is one order of magnitude larger in comparison with pure $\mathrm{Mg}$. This is most likely caused due to higher stresses needed to break the WE43 protective layer and, universally, high reactivity of the WE43 alloy, leading to stronger AE response. This result also agrees with a distinct increase in the corrosion current in the potential-current curve in comparison with pure $\mathrm{Mg}$.

The present study shows that contemporary AE analyses are capable of effective monitoring of corrosion dynamics in magnesium and its alloys, providing unique in-situ information about the corrosion processes in the microsecond time scale. Representative AE parameters for the threshold-based AE monitoring can be discriminated. The advanced clustering ASK analysis, which evaluates the AE signal in the frequency domain, is able to recognise and follow individual mechanisms underlying the corrosion in $\mathrm{Mg}$. Furthermore, the AE technique is a non-destructive and passive method suitable for real-time measurements. The presented methods can be most likely applied to different metals and their alloys and possibly used as an on-site industrial monitoring tool. 


\section{Conclusions}

The acoustic emission technique was effectively applied for the monitoring of corrosion in pure magnesium and WE43 magnesium alloy during anodic polarisation in $0.1 \mathrm{M} \mathrm{NaCl}$ aqueous solution. Two methods, i.e. the standard threshold-based signal detection and the recently developed ASK clustering technique provide complementary information on corrosion processes. The proposed methods can be potentially employed for different materials and for industrial in-situ corrosion monitoring. The main results of this study can be summarised as follows:

- The acoustic emission parameters suitable for the monitoring of corrosion in $\mathrm{Mg}$ and $\mathrm{Mg}$ alloys are the AE counts, rise time, and duration. The growth of stable pits is characterised by resonant, high energy AE signals. Earlier stages of corrosion give rise to burst-like AE signals of lower intensity.

- The main sources of AE during potentiodynamic polarisation of both materials were identified to be the ion exchange, the rupture of the protective film initiating metastable pits, and the pitting corrosion, i.e. the growth of stable pits.

- When compared with pure $\mathrm{Mg}$, stronger protective layer is formed on the surface of the WE43 alloy. On the other hand, the WE43 alloy exhibits higher reactivity, which gives rise to a more intensive $\mathrm{AE}$ response.

- In addition, the evolution and differences in the activity of individual corrosion mechanisms during the tests was effectively identified by the ASK clustering algorithm. Therefore, this method provides additional in-situ information with exceptional temporal resolution on the dynamics of corrosion activity, which cannot be captured by the potentiodynamic tests and the evaluation of only basic AE parameters.

\section{Data availability}

The raw and the processed data required to reproduce these findings will be made available on request.

\section{Acknowledgements}

This work was financially supported by the Czech Science Foundation (project No. 14-13415S). Partial financial support by ERDF under the project No. CZ.02.1.01/0.0/0.0/15 003/0000485 is also gratefully acknowledged.

\section{Bibliography}

[1] Mordike, B.L., 2002. Creep-resistant magnesium alloys. Materials Science and Engineering: A 324, pp. 103-112.

[2] Antion, C., Donnadieu, P., Perrard, F., Deschamps, A., Tassin, C., Pisch, A., 2003. Hardening precipitation in a Mg-4Y-3RE alloy. Acta Materialia 51(18), pp. 5335-5348. doi:10.1016/S1359-6454(03)00391-4

[3] Nie, J.F., Muddle, B.C., 2000. Characterisation of strengthening precipitate phases in a MgY-Nd alloy, Acta Materialia 48(8), pp. 1691-1703. doi:10.1016/S1359-6454(00)00013-6 
[4] Janeček, M., Král, R., Dobroň, P., Chmelík, F., Šupík, V., Holländer, F., 2007. Mechanisms of plastic deformation in AZ31 magnesium alloy investigated by acoustic emission and transmission electron microscopy. Materials Science and Engineering: A 462, pp. 311-315. doi:10.1016/j.msea.2006.01.172

[5] Mengucci, P., Barucca, G., Riontino, G., Lussana, D., Massazza, M., Ferragut, R., Aly, E.H., 2008. Structure evolution of a WE43 Mg alloy submitted to different thermal treatments. Materials Science and Engineering: A 479, pp. 37-44. doi:10.1016/j.msea.2007.06.016

[6] Zeng, R.C., Zhang, J., Huang, W., Dietzel, W., Kainer, K.U., Blawert, C., Ke, W., 2006. Review of studies on corrosion of magnesium alloys, Transactions of Nonferrous Metals Society of China 16(2), pp. 763-771. doi:10.1016/S1003-6326(06)60297-5

[7] Chu, P.-W., Marquis, E.A., 2015. Linking the microstructure of a heat-treated WE43 Mg alloy with its corrosion behavior. Corrosion Science 101, pp. 94-104. doi:10.1016/j.corsci.2015.09.005

[8] Ascencio, M., Pekguleryuz, M., Omanovic, S., 2014. An investigation of the corrosion mechanisms of WE43 Mg alloy in a modified simulated body fluid solution: The influence of immersion time. Corrosion Science 87, pp. 489-503. doi:10.1016/j.corsci.2014.07.015

[9] Burstein, G.T., Liu, C., 2007. Nucleation of corrosion pits in Ringer's solution containing bovine serum. Corrosion Science 49, pp. 4296-4306. doi:10.1016/j.corsci.2007.05.018

[10] Orlikowski, J., Darowicki, K., 2011. Investigations of pitting corrosion of magnesium by means of DEIS and acoustic emission. Electrochimica Acta 56, pp. 7880-7884. doi:10.1016/j.electacta.2010.12.021

[11] Prateepasen, A., 2012. Pitting Corrosion Monitoring Using Acoustic Emission, In: Pitting Corrosion, Bensalah, N. (Ed.), InTech. doi:10.5772/33127

[12] Song, G.L., Atrens, A., 1999. Corrosion Mechanisms of Magnesium Alloys. Advanced Engineering Materials 1, pp. 11-33. doi:10.1002/(SICI)1527-2648(199909)1:1<11::AIDADEM11>3.0.CO;2-N

[13] Ascencio, M., Pekguleryuz, M., Omanovic, S., 2015. An investigation of the corrosion mechanisms of WE43Mg alloy in a modified simulated body fluid solution: The effect of electrolyte renewal. Corrosion Science 91, pp. 297-310. doi:10.1016/j.corsci.2014.11.034

[15] Liu, M., Zanna, S., Ardelean, H., Frateur, I., Schmutz, P., Song, G., Atrens, A., Marcus, P., 2009. A first quantitative XPS study of the surface films formed, by exposure to water, on $\mathrm{Mg}$ and on the $\mathrm{Mg}-\mathrm{Al}$ intermetallics: $\mathrm{Al} 3 \mathrm{Mg} 2$ and Mg17Al12. Corrosion Science 51, pp. 1115-1127. doi:10.1016/j.corsci.2009.02.017

[16] Taheri, M., Phillips, R.C., Kish, J.R., Botton, G.A., 2012. Analysis of the surface film formed on $\mathrm{Mg}$ by exposure to water using a FIB cross-section and STEM-EDS. Corrosion Science 59, pp. 222-228. doi:10.1016/j.corsci.2012.03.001

[17] Zucchi, F., Grassi, V., Frignani, A., Monticelli, C., Trabanelli, G., 2006. Electrochemical behaviour of a magnesium alloy containing rare earth elements. Journal of Applied Electrochemistry 36, pp. 195-204. doi:10.1007/s10800-005-9053-3 
378 the role of alloying. International Materials Reviews 60, pp. 169-194. doi:10.1179/1743280414Y.0000000046

380 [19] Ardelean, H., Seyeux, A., Zanna, S., Prima, F., Frateur, I., Marcus, P., 2013. Corrosion processes of $\mathrm{Mg}-\mathrm{Y}-\mathrm{Nd}-\mathrm{Zr}$ alloys in Na2SO4 electrolyte. Corrosion Science 73, pp. 196-207. doi:10.1016/j.corsci.2013.03.036

383

384

385

386

387

388

389

390

391

392

393

394

395

396

397

398

399

400

401

402

403

404

405

406

407

408

409

410

411

412

413

414

415

416

[20] Bender, S., Goellner, J., Heyn, A., Schmigalla, S., 2012. A new theory for the negative difference effect in magnesium corrosion. Materials and Corrosion 63, pp. 707-712. doi:10.1002/maco.201106225

[21] Thomaz, T.R., Weber, C.R., Pelegrini, T., Dick, L.F.P., Knörnschild, G., 2010. The negative difference effect of magnesium and of the AZ91 alloy in chloride and stannate-containing solutions. Corrosion Science 52, pp. 2235-2243. doi:10.1016/j.corsci.2010.03.010

[22] Máthis, K., Chmelík, F., 2012. Exploring plastic deformation of metallic materials by the acoustic emission technique. In: Acoustic Emission, Sikorski, W. (Ed.), InTech. doi: $10.5772 / 31660$

[23] Mazille, H., Rothea, R., Tronel, C., 1995. An acoustic emission technique for monitoring pitting corrosion of austenitic stainless steels. Corrosion Science 37, pp. 1365-1375. doi:10.1016/0010-938X(95)00036-J

[24] Fregonese, M., Idrissi, H., Mazille, H., Renaud, L., Cetre, Y., 2001. Monitoring pitting corrosion of AISI 316L austenitic stainless steel by acoustic emission technique: choice of representative acoustic parameters. Journal of materials science 36, pp. 557-563. doi:10.1023/A:1004891514836

[25] Fregonese, M., Idrissi, H., Mazille, H., Renaud, L., Cetre, Y., 2001. Initiation and propagation steps in pitting corrosion of austenitic stainless steels: monitoring by acoustic emission. Corrosion Science 43, pp. 627-641. doi:10.1016/S0010-938X(00)00099-8

[26] Bellenger, F., Mazille, H., Idrissi, H., 2002. Use of acoustic emission technique for the early detection of aluminum alloys exfoliation corrosion. NDT \& E International 35, pp. 385-392. doi:10.1016/S0963-8695(02)00011-7

[27] Kim, Y., Fregonese, M., Mazille, H., Féron, D., Santarini, G., 2003. Ability of acoustic emission technique for detection and monitoring of crevice corrosion on $304 \mathrm{~L}$ austenitic stainless steel. NDT \& E International 36, pp. 553-562. doi:10.1016/S0963-8695(03)00065-3

[28] Prateepasen, A., Jirarungsatean, C., Tuengsook, P., 2006. Identification of AE Source in Corrosion Process. Key Engineering Materials 321-323, pp. 545-548. doi:10.4028/www.scientific.net/KEM.321-323.545

[29] Prateepasen, A., Jirarungsatian, C., 2011. Implementation of acoustic emission source recognition for corrosion severity prediction. Corrosion $67,056001-1$.

[30] Bi, H., Li, Z., Hu, D., Toku-Gyamerah, I., Cheng, Y., 2015. Cluster analysis of acoustic emission signals in pitting corrosion of low carbon steel: Clusteranalyse des Schallemissionssignals bei Lochkorrosion von niedrig legiertem Stahl. Materialwissenschaft und Werkstofftechnik 46, pp. 736-746. doi:10.1002/mawe.201500347 
[31] Morizet, N., Godin, N., Tang, J., Maillet, E., Fregonese, M., Normand, B., 2016. Classification of acoustic emission signals using wavelets and Random Forests : Application to localized corrosion. Mechanical Systems and Signal Processing 70-71, pp. 1026-1037. doi:10.1016/j.ymssp.2015.09.025

[32] Esmaily, M., Svensson, J.E., Fajardo, S., Birbilis, N., Frankel, G.S., Virtanen, S., Arrabal, R., Thomas, S., Johansson, L.G., 2017. Fundamentals and advances in magnesium alloy corrosion. Progress in Materials Science 89, pp. 92-193. doi:10.1016/j.pmatsci.2017.04.011

[33] Zhou, H.M., Wang, J.Q., Zang, Q.S., Han, E.H., 2007. Study on the Effect of $\mathrm{Cl}^{-}$ Concentration on the Corrosion Fatigue Damage in a Rolled AZ31B Magnesium Alloy by Acoustic Emission. Key Engineering Materials 353-358 (Part 1), pp. 327-330. doi:10.4028/www.scientific.net/KEM.353-358.327

[34] Minárik, P., Landa, M., Lesná, I.K., Zemková, M., Jablonská, E., Hadzima, B., Janeček, M., Král, R., 2015. Interrelation of Microstructure and Corrosion Resistance in Biodegradable Magnesium Alloys with Aluminum, Lithium and Rare Earth Additions. Acta Physica Polonica A 128, pp. 491-497. doi:10.12693/APhysPolA.128.491

[35] Sustr, M., Zacal, J., Dostal, P., Sriwongras, P., 2015. The Corrosion Resistivity Monitoring of Magnesium Alloy by the Acoustic Emission. MendelNet, pp. 557-561.

[36] Pomponi, E., Vinogradov, A., 2013. A real-time approach to acoustic emission clustering. Mechanical Systems and Signal Processing 40, pp. 791-804. doi:10.1016/j.ymssp.2013.03.017

[37] Vinogradov, A., Orlov, D., Danyuk, A., Estrin, Y., 2015. Deformation mechanisms underlying tension-compression asymmetry in magnesium alloy ZK60 revealed by acoustic emission monitoring. Materials Science and Engineering: A 621, pp. 243-251. doi:10.1016/j.msea.2014.10.081

[38] Máthis, K., Csiszár, G., Čapek, J., Gubicza, J., Clausen, B., Lukáš P., Vinogradov, A., Agnew, S.R., 2015. Effect of the loading mode on the evolution of the deformation mechanisms in randomly textured magnesium polycrystals - Comparison of experimental and modeling results. International Journal of Plasticity 72, pp. 127-150. doi:10.1016/j.ijplas.2015.05.009

[39] Alamdari, M.M., Rakotoarivelo, T., Khoa, N.L.D, 2017. A spectral-based clustering for structural health monitoring of the Sydney Harbour Bridge, Mechanical Systems and Signal Processing 87 A, pp. 384-400, doi:10.1016/j.ymssp.2016.10.033

[40] Cain, T., Bland, L.G., Birbilis, N., Scully, J.R., 2014. A Compilation of Corrosion Potentials for Magnesium Alloys. Corrosion 70, pp. 1043-1051. doi:10.5006/1257

[41] Maier, P., Peters, R., Mendis, C.L., Müller, S., Hort, N., 2016. Influence of Precipitation Hardening in Mg-Y-Nd on Mechanical and Corrosion Properties. JOM 68, pp. 1183-1190. doi:10.1007/s11837-015-1762-4

[42] Wu, K., Jung, W.-S., Byeon, J.-W., 2015. Acoustic emission of hydrogen bubbles on the counter electrode during pitting corrosion of 304 stainless steel. Materials Transactions 56, pp. 587-592. doi:10.2320/matertrans.M2014373 